\title{
The Child as Organ and Tissue Donor: Discussions in the Danish Council of Ethics
}

\author{
SØREN HOLM
}

At the end of 1999 the Danish Council of Ethics published a report on organ and tissue donation from living donors. ${ }^{1}$ The report focused on kidney and bone marrow transplantations (BMTs), as these are presently the most common transplantations from live donors. During the work on the report, it became clear to the Council that, apart from problems concerning coercion and commercialization that affected both adult and child donors, by far the largest ethical problems occurred in donations from children.

In this article I briefly review some of the arguments that were prominent in the Council's deliberations. It is, however, important from the outset to state that the final recommendations endorsed by the majority of the Council are fairly conventional:

1. Kidney donation should be prohibited from donors under the age of 18, but over that age no restrictions should be applied with regard to degree of family relationship.

2. No lower age limit should be put in place with regard to bone marrow donation. Children over the age of 15 should be allowed to give consent to donation. For children under the age of 15 , consent must be given by the parents, but the opinions of the child should be given more weight the older the child is. All child donors should have access to adequate psychological and social support. There should be no restrictions concerning family relationship between donor and recipient.

3. Increased resources should be allocated to the expansion of the Danish BMT register to increase the chances of identifying a matching anonymous bone marrow donor.

These recommendations are broadly in accordance with the provisions concerning live donation in the Bioethics Convention of the Council of Europe. The only major discrepancy is that the Danish Council of Ethics does not support the Convention's provision in article 20.2 that BMT from a minor can only be performed if the recipient is a sibling of the donor. The Council found that no compelling reasons could be found to prohibit donation to a parent, other close relative, or friend.

\section{Do We Forget the Donor?}

The first topic that caught the attention of the Council was the (lack of) support for child donors before and especially after the actual donation. The Council 
performed an extensive literature review of the available empirical literature concerning psychological and sociological effects of live organ donation. ${ }^{2-13}$ This literature review led to four conclusions:

1. The literature on psychological and social effects of live donation is surprisingly small, and the section of the literature concerned with child donors even smaller.

2. Giving an organ within a family is not a simple case of gift giving. An organ cannot be moved from one family member to another without often-profound consequences for the family dynamics.

3. Anonymous donation is much less psychologically complicated than family donation.

4. Child donors often feel neglected after the donation, where the attention of the family is still focused on the recipient.

Seen from a theoretical perspective, the gift being given when one gives an organ or lifesaving tissue is of a magnitude that makes it very difficult for the recipient to reciprocate with a gift of similar importance. ${ }^{14}$ According to the normal logic of gifts, a gift must be reciprocated at some later point in time by a different gift of the approximately same value as the first gift. If this is impossible, it may have two problematic consequences: either the giver feels that he has a residual claim on the recipient, or the recipient feels that she still owes the donor something. Both types of perceived residual obligations can have profound consequences for the relationship between family members, and these can be further complicated by nondonors being jealous of the donor.

Most child donors give bone marrow to siblings or parents, and this introduces further complications. In most cases, the focus of attention in the family has for a long time been the person who is ill, and the healthy child may already feel neglected before the donation. After the transplant, the focus is even more concentrated on the recipient. He is gravely ill, and everybody is anxiously waiting to see whether the new bone marrow will take. The donor, therefore, often receives even less attention in the immediate posttransplantation period than before the transplant. In many cases, this creates a feeling of rejection and of not getting appropriate recognition for a truly good and altruistic act.

The Danish Council of Ethics surveyed the psychological and social support given to child donors in Danish and other Nordic BMT units and found it to be almost nonexistent. Apparently, it is believed that, because BMT donation is a medically uncomplicated procedure, even in very small children, it is also psychologically uncomplicated and that the necessary aftercare can be left to the parents of the donor. The Council did, however, after careful consideration of the evidence reach the view that this is not true in many instances, precisely because the parents and other family members often have to divide their attention between the donor and the recipient. It is also often the case that the family underestimates the needs of the donor.

\section{Possible Restrictions on Donations from Children}

A topic that is often discussed in connection with organ donation from child donors is whether there should be restrictions with regard to either the age of 
the donors or the range of recipients. Most of the arguments are based on worries about whether children may in certain circumstances be used as mere means to achieving the goals of other people. In the discussions of the Danish Council of Ethics these types of arguments were also prominent, but two other arguments were proposed that have not been prominent in the literature. In the end, both arguments failed to convince the majority of the Council, but they are nevertheless interesting because they both represent a departure from a predominantly individualistic analysis of the child donation issues.

The first of these arguments would restrict live organ donations to donations from parents or grandparents to children, and thereby prohibit most child donations, except those from teenage parents to their children. It is based on an analysis of the three archi-prohibitions that are necessary for the constitution of a stable human society. For a society to exist, it is necessary to have prohibitions against:

- incest,

- murder, and

- cannibalism.

These prohibitions are primordial but they are not natural; they are socially constructed, but they are nevertheless necessary for societal stability. We do not have sex with our relatives, we do not kill each other, and we do not eat each other (but the extension of "we" is always open for discussion and construction). ${ }^{15}$ One possible understanding of organ and tissue transplantation is to see it as a form of nonoral cannibalism. The recipient incorporates (or perhaps more accurately, incarnates) the flesh of another to (re)gain health and strength. According to this analysis, transplantation becomes problematic because the practice is in potential conflict with one of the archi-prohibitions. Initially, this may seem to preclude all transplantations, or at least all transplantations where the recipient permanently incorporates a part of the donor (thereby exempting blood transfusions), but a possible exception would be transplantations between persons who are "of the same flesh." In such cases, it is not the flesh of another I incorporate but the flesh of myself. It can thus be argued that the only allowable form of transplantation involving live donors is transplantation from parents (or grandparents) to children, given that children can be said to be of the flesh of their parents (but note that the relation is not reflexive; parents are not of the flesh of their children). A further argument for this position could be that, whereas we have legitimate expectations that parents should in appropriate circumstances sacrifice substantially for their children, our expectations concerning the appropriate sacrifices of children are much more limited.

The second argument results in a restriction of the possibility to donate nonregenerable tissue (like kidneys or liver lobes) that can only be donated once in a lifetime to people who have already reached a stage in the life cycle where they have established their own family. This argument is based on the observations that (1) by donating a nonregenerable organ a person preempts the opportunity of ever again donating the same organ, and that (2) during the life cycle our family attachments and obligations change. When we are young and have not yet formed our own family, our main attachment is to our parental family unit (parents and siblings), but when we later form our own family unit and become parents, the main attachment changes to our partner 
and children. If young people are allowed to be organ donors, they may not accurately be able to predict this change of attachments and obligations and may not therefore be able to predict the regret they may later feel if they "need" to be able to donate the organ to, for instance, their child and are not able to do so. Such changes in preferences are, in a certain sense, predictable. They can be predicted by the impartial outside observer, but they at the same time have the property that, although they are predictable, they are seldom foreseen by the agent herself, or the agent misjudges their likely strength. It can therefore be argued that organ donation from children or young persons is a situation where rational decisionmaking in the form of maximization of expected utility (i.e., standard von Neumann-Morgenstern rational choice) is likely to be problematic because of radical, predictable, but not expected (by the agent) changes in preferences (and thereby utilities) over time.

It is an obvious fact that the time in life when a person knows that he will (or will not) form a family differs from person to person, and that it can be very difficult to fix exactly when this has occurred. As a pragmatic solution, it was proposed to restrict organ donation to adults 35 years or older. At that age, most people know whether they are going to have children, and they know how their adult relationship with their parents is going to be.

In the end, none of these arguments convinced the majority of members in the Danish Council of Ethics to propose restrictions on donation from children. But the arguments nevertheless point to the fact, that although organ transplantation may now be a routine, uncomplicated medical procedure, it is not uncomplicated if all social and psychological consequences are taken into account.

\section{Notes}

1. Det Etiske Råd. Levende donorer: en redegørelse om nyredonation og knoglemarvsdonation. Copenhagen: Det Etiske Råd; 1999. Available at: http://www.etiskraad.dk. The conclusions of the report will be printed in the English language 1999 annual report of the Danish Council of Ethics, but the full report will not appear in English translation.

2. Simmons RG, Marine SK, Simmons RL. Gift of Life: The Effect of Organ Transplantation on Individual, Family, and Societal Dynamics. New Brunswick, NJ: Transaction; 1987.

3. Price D, Akveld H. Living donor organ transplantation in Europe: re-evaluating its role. European Journal of Health Law 1998;5:19-44.

4. Westlie L, Fauchald P, Talseth T, Jakobsen A, Flatmark A. Quality of life in Norwegian kidney donors. Nephrology Dialysis Transplantation 1993;8:1146-50.

5. Kärfelt HME, Berg UB, Lindblad FIE, Tyden G. To be or not to be a living donor. Transplantation 1998;65(7):915-8.

6. Packman WL, Crittenden MR, Schaeffer E, Bongar B, Fischer JB, Cowan MJ. Psychosocial consequences of bone marrow transplantation in donor and nondonor siblings. Developmental and Behavioral Pediatrics 1997;18(4):244-53.

7. Packman WL, Crittenden MR, Fischer JB, Schaeffer E, Bongar B, Cowan MJ. Siblings' perceptions of the bone marrow transplantation process. Journal of Psychosocial Oncology 1997;15(3/4):81-105.

8. Phipps S, Mulhern RK. Family cohesion and expressiveness promote resilience to the stress of pediatric bone marrow transplant: a preliminary report. Development and Behavioral Pediatrics 1995;4:257-63.

9. Freund BL, Siegel K. Problems in transition following bone marrow transplantation: psychological aspects. American Journal of Orthopsychiatry 1986;56(2):244-52.

10. Wiley F, Lindamood MM, Pfefferbaum-Levine B. Donor-patient relationship in pediatric bone marrow transplantation. Journal of the Association of Pediatric Oncology Nurses 1984;1(3):8-14. 


\section{Søren Holm}

11. Gardner GG, August CS, Githens J. Psychological issues in bone marrow transplantation. Pediatrics 1977;60(4, part 2):625-31.

12. Butterworth VA. When altruism fails: reactions of unrelated bone marrow donors when the recipient dies. OMEGA 1993;26(3):161-73.

13. Pot-Mees CC. The Psychosocial Effects of Bone Marrow Transplantation in Children. Delft, the Netherlands: Eburon; 1989.

14. Siminoff LA, Chillag K. The fallacy of the "gift of life." Hastings Center Report 1999;29(6):34-41.

15. Schmidt LH. Immediacy Lost: Construction of the Social in Rousseau and Nietzsche. Copenhagen: Akademisk Forlag; 1988. 